\title{
Secondary xylem maturation evaluated by modeling radial variations in anatomical characteristics and wood properties of Shorea macrophylla (De Vr.) Ashton planted in Sarawak, Malaysia
}

\author{
Ikumi Nezu ${ }^{1,2} \cdot$ Futoshi Ishiguri $^{1}\left(10\right.$ ) Haruna Aiso ${ }^{3} \cdot$ Yuichiro Hiraoka $^{3} \cdot$ Mohd Effendi Wasli $^{4} \cdot$ Tatsuhiro Ohkubo $^{1}$. \\ Jyunichi Ohshima ${ }^{1} \cdot$ Shinso Yokota ${ }^{1}$
}

Received: 6 August 2021 / Accepted: 30 October 2021

(c) The Author(s), under exclusive licence to Springer-Verlag GmbH Germany, part of Springer Nature 2021

\begin{abstract}
Key message Xylem maturation depends on cambial age rather than diameter growth in Shorea macrophylla by the model selections for radial variations in cell length, wood fiber traits, and basic density.

Abstract Radial variations in anatomical characteristics and wood properties were investigated in 23-year-old Shorea macrophylla (engkabang) trees planted in Sarawak, Malaysia. The effects of radial growth rates on anatomical characteristics and wood properties and the manner of xylem maturation were determined based on selected mixed-effects models. The best models of radial variation were fitted by linear functions for wood fiber length, wood fiber wall thickness, basic density, and compressive strength. Logarithmic functions were applied for vessel element length and vessel frequency, and quadratic functions were applied for vessel diameter and wood fiber diameter. Vessel diameter and wood fiber length were affected by radial growth rates although these effects on the other properties were minimal. In the fixed part of the models, the results showed small mean absolute error values of radial variation in relation to the distance from the pith according to vessel frequency and vessel diameter. In contrast, in relation to the estimated cambial age, smaller mean absolute error values were obtained for cell length, wood fiber traits, and basic density, suggesting that all properties varied from pith to bark in relation to the cambial age, except for vessel traits. Thus, in S. macrophylla, xylem maturation in cell length, wood fiber traits, and basic density were due to cambial age rather than diameter growth, but xylem maturation in vessel traits depended on diameter growth.
\end{abstract}

Keywords engkabang $\cdot$ Radial variation $\cdot$ Radial growth rate $\cdot$ Xylem maturation $\cdot$ Mixed-effects model

\section{Introduction}

Communicated by Ingo Burgert .

Futoshi Ishiguri

ishiguri@cc.utsunomiya-u.ac.jp

1 School of Agriculture, Utsunomiya University, 321-8505 Utsunomiya, Japan

2 United Graduate School of Agricultural Science, Tokyo University of Agriculture and Technology, 183-8509 Fuchu, Tokyo, Japan

3 Faculty of Agricultural Production and Management, Shizuoka Professional University of Agriculture, 438-8577 Iwata, Japan

4 Faculty of Resource Science and Technology, Universiti Malaysia Sarawak, 94300 Kota Samarahan, Malaysia
The xylem maturation process in tropical broad-leaved tree species has been evaluated based on radial variations in anatomical characteristics and wood properties in individual trees with different radial growth rates (Ohbayashi and Shiokura 1990; Bhat et al. 2001; Honjo et al. 2005; Chowdhury et al. 2009; Kojima et al. 2009a, b; Makino et al. 2012; Ishiguri et al. 2012, 2016; Hidayati et al. 2017; Pertiwi et al. 2017, 2018; Nezu et al. 2020). Although the results of several previous studies on fast-growing tree species were obtained using a limited number of samples and young trees less than 10 years old, the xylem maturation process in tropical broad-leaved tree species can be divided into two types: anatomical characteristics and wood properties stabilized in relation to the following: (1) diameter growth (Ohbayashi and Shiokura 1990; Honjo et al. 2005; Chowdhury et al. 